\title{
Significance of Standoff Distance on Character Features of Detonation Spray Alumina on Unhardened EN 19 Steel
}

\author{
${ }^{1}$ V.P. Haridasan, ${ }^{2}$ A. Velayudham and ${ }^{3}$ R. Krishnamurthy \\ ${ }^{1}$ Department of Mechanical Engineering, \\ Dr. M.G.R. Educational and Research Institute University, \\ Periyar E.V.R High Road, Maduravoyal, 600095 Chennai, Tamil Nadu, India \\ ${ }^{2}$ Combat Vehicles Research and Development Establishment, Avadi, \\ 600054 Chennai, Tamil Nadu, India \\ ${ }^{3}$ Indian Institute of Technology Madras, Manufacturing Engineering Section, \\ 600036 Chennai, Tamil Nadu, India
}

\begin{abstract}
Coating of ceramic material is a promising approach to modify the surface characteristics of low alloy steels. Detonation spraying is widely employed to coat alumina ceramic powder for wear resistance applications. To study the efficacy of the spraying it is essential to characterize the coating. This study elucidates the significance of standoff distance on character features of detonation sprayed alumina on unhardened EN19 steel. In this study, experimental results are presented in terms of micro hardness, coating thickness and XRD patterns of detonation sprayed alumina coatings as a function of standoff. The highest hardness value occurs at the spraying distance of $220 \mathrm{~mm}$ and corresponding SEM micrograph indicates denser microstructure. Presence of $\gamma-\mathrm{Al}_{2} \mathrm{O}_{3}$ in the coated surface in addition to $\alpha-\mathrm{Al}_{2} \mathrm{O}_{3}$ phase indicates tenacious nature of deposition.
\end{abstract}

Key words: Detonation spray, EN19 steel, standoff, XRD, microhardness, SEM

\section{INTRODUCTION}

Currently surface characteristicsof low strength steel materials are being modified by coating ceramic materials to enhance wear properties in an economical way. Ceramic coating is avery promising approach to tailor the surface properties ofmetal component due to their high hardness, excellent wear, corrosion, as well as chemical and thermal resistance (Wang et al., 2013). Of the ceramic materials, alumina is mostly preferred due to their excellent wear resistance and strength retention at higher temperature of about $1100^{\circ} \mathrm{C}$ besides economical consideration. Thermal spray processes such as detonation-gun, plasma and highvelocity oxy-fuel spraying methods are mostlyused to apply coating to impart wear resistance againstabrasion and erosion in corrosive environment at hightemperature (Chatha et al., 2012; Kucuk et al., 2001). Detonation spray processis a thermal spray coating process which gives an extremely good adhesive strength, low porosity, higher coating thickness and coating surfacewith compressive residual stresses (Singh et al., 2012). Unlike plasma spray, detonation spray calls for fine grain size, ensuring thereby denser deposition with enhanced inter-lamellar cohesion. Characterization of microstructures facilitates to understand the thermo-mechanical evolution of the coating and bonding mechanisms at the interface between substrate and coating (Srinivasan, 2016). This study elucidates the significance of standoff distance on the characteristic features of detonation sprayed alumina coatings on the EN19 unhardened steel.

During detonation spraying, the coating particles are injected into a combustion flameand become plasticized due to heating and detonated subsequently on the substrate. The plasticized particles upon impingement rapidly solidify and form splat. Investigations on detonation spraying have revealed that Alumina $\left(\mathrm{Al}_{2} \mathrm{O}_{3}\right)$ deposits are superior considering the weak adhesive strength of other coatings (Balan and Ramesh Bapu, 2012). Observation of broadened peaks of XRD patterns are due to stronger impingement of spraying particles and internal strain during cooling (Wang et al., 2009). Deposition of WC-Co powder doped with $\mathrm{MoS}_{2}-\mathrm{Ni}$ powder by detonation spray process exhibited higher

Corresponding Author: A. Velayudham, Combat Vehicles Research and Development Establishment, Avadi, 600054 Chennai, Tamil Nadu, India 
sliding wear resistance and lower coefficient of friction (Du et al., 2007). Detonation sprayed Ni-5Al on Inconel 718 was characterised through X-ray diffraction, SEM/EDAX and X-ray mapping techniques to analyse cyclic hot corrosion resistance. The detonation spraying process was found to produce a uniform, dense and adherent coating (Saladi et al., 2015). This is largely due to environmental influence over the deposition of carbides and nitrides, especially in atmospheric spraying. Durability and functional characteristics of the coatings were influenced by porosity of the thermally sprayed ceramic coatings ( $\mathrm{Li}$ and Ohmori, 1996). HVOF and detonation spraying were compared by spraying MCrAlYX. Redistribution of elements, formation of lamellar microstructure and compressive residual stress between the coating and substrate were found to contribute higher bonding strength in the detonation spraying of McrAlYX (Gao et al., 2015). $\mathrm{Al}_{2} \mathrm{O}_{3}$ layers deposited by detonation spraying formed as lamellar structure. The inter-lamellar cohesion and associated voids dictate soundness of the deposits ( $\mathrm{Li}$ and Ohmori, 2002). Investigations on sliding wear characteristics of detonation sprayed alumina based ceramic composite coatings exhibited least sliding wear under higher temperature environment (Kumar et al., 2011). Surface morphology of alumina-titania coated through plasma and detonation spray was characterized using a Scanning Electron Microscope (SEM) and tribo-corrosion study showed lower porosity with detonation spray (Rathore et al., 2013). This is attributed to the difference in the formation of deposition between plasma and detonation spraying. While plasma spraying is a dominant thermal process, detonation spray is relatively higher velocity process wherein the plasticized particles with flame undergoes splat cooling on detonation over the substrate. This lead to less change in stoichiometry and relatively denser deposition. The investigation on the variation in the microstructure and phase changes of the sprayed deposits, reveals that chemical transformation forming minor phases lead to the strengthening of the deposits and consequently higher hardness (Dudina et al., 2015). Alumina deposits when paired with hardened steel exhibit increased sliding wear due to chemical interaction at higher temperature and the strain associated wear mechanism (Geetha et al.,
2014). This could be due to the status of the deposition including porosity and interlamellar cohesion.

\section{MATERIALS AND METHODS}

Work material: EN19 steel (BS:970) whose composition is given in Table 1 has been taken as substrate material. This material is widely used as component material in the development of hydraulic cylinders. Cylindrical specimens of size $10 \mathrm{~mm}$ diameter and $30 \mathrm{~mm}$ length were prepared and subsequently grit blasted to roughen the outer layer of the substrates to facilitate better mechanical keying/locking of the sprayed layers.

Coating material: Alumina a widely used material for wear resistant applications is chosen as coating material. CUMI make alumina powder which is of $99.97 \%$ purity and aparticle size of $20-30 \mu \mathrm{m}$ was used for detonation spraying. The performance of the coating largely depends on fuel/oxygen ratio, particle size of powder, flow rate of carrier gas, frequency of detonation and standoff, i.e., the distance between the substrate and end of detonation gun barrel. It is to be noted that unlike the case of plasma spray wherein higher standoff results in oxidisation and other atmospheric influence over sprayed material with detonation spray, higher the standoff, i.e., residence time, better will be the interaction within combustion flame and enhances plasticization of spray material. The employed parameters for detonation spraying are listed in Table 2.

The hardness on the sprayed surface was measured using Vickers Hardness Tester, Model No. VM50 (Fuel Instruments Engineers Pvt. Ltd.) at a load of $200 \mathrm{gf}$. The microstructure of the sprayed coatings was observed by using Quanta FEG scanning electron microscope, Model No. 200. To identify the phases formed during detonation spraying, XRD analysis was performed on the as-sprayed surface. The coated specimens were polished and analysed through SEM. To study the performance of the detonation spraying of alumina, the tribological characteristics of sprayed deposition (friction and wear) was evaluated in a rotary tribometer, Model No. TR201 (DUCOM instruments Pvt. Ltd., India) as per ASTM G99-04. Wear tests were performed by keeping wear track as $80 \mathrm{~mm}$, load as $15 \mathrm{~N}$ and sliding velocity as $1 \mathrm{~m} / \mathrm{sec}$. The counter surface is EN31 steel, hardened to $60 \mathrm{Hrc}$.

Table 1: Chemical composition of work material (\%)

\begin{tabular}{lllllll}
\hline Material & $\mathrm{C}$ & $\mathrm{Mn}$ & $\mathrm{Cr}$ & $\mathrm{Mo}$ & $\mathrm{Si}$ & $\mathrm{S}$ \\
\hline EN19 steel to BS:970 & $0.35-0.45$ & $0.50-0.80$ & $0.90-1.40$ & $0.20-0.40$ & $0.10-0.35$ & 0.40 \\
\hline
\end{tabular}


Table 2: Detonation spraying parameters

\begin{tabular}{ll}
\hline Parameters & Values \\
\hline Oxygen $\left(\mathrm{O}_{2}\right)$ flow rate & $0.08 \mathrm{~m}^{3} / \mathrm{min}$ \\
Acetylene $\left(\mathrm{C}_{2} \mathrm{H}_{2}\right)$ flow rate & $0.03 \mathrm{~m}^{3} / \mathrm{min}$ \\
Carrier gas pressure & $73.4 \mathrm{kPa}$ \\
Detonation frequency & $3 \mathrm{shots} / \mathrm{sec}$ \\
Standoff distance & 180,200 and $220 \mathrm{~mm}$ \\
Powder feed rate & $1.0-1.4 \mathrm{~g} / \mathrm{sec}$ \\
Spray angle & $90^{\circ}$ \\
\hline
\end{tabular}

\section{RESULTS AND DISCUSSION}

Micro hardness and coating thickness: The significance of standoff distance on coating thickness and microhardness of the detonation spray deposition can be seen in Fig. 1. It is seen that coating thickness tending to rise for standoff above $200 \mathrm{~mm}$ indicating less fragmentation and formation of dense structure. This is reflected by progressive rise in microhardness with standoff distance. Microhardness value ranges from 975-1150 Hv. Occurrence of highest microhardnesswas observed at the standoff distance of $220 \mathrm{~mm}$ for the coatings deposited. The resulted higher hardness at this standoff indicates denser microstructure as seen from SEM micrograph (Fig. 2-12). The coating thickness initially decreases up to $200 \mathrm{~mm}$ standoff and thereafter it rises steadily.

Observation of XRD influence on standoff: Scanning electron microscope and EDS were utilised to study the morphology of the alumina powder and sprayed surfaces. Typical surface morphology and XRD pattern of the uncoated alumina powder is shown in Fig. 2 and 3. It can be seen that the powder is crystalline and mainly composed of $\alpha$-phase of $\mathrm{Al}_{2} \mathrm{O}_{3}$. From the XRD pattern of D-gun sprayed coating (Fig. 4-6) it is seen that in addition to $\alpha$-phase, $\gamma$-phase alumina is also observed.

In the case of atmospheric spraying, a distinct change in the status of spraying between plasma and detonation as influenced by standoff could be seen. Normally standoff influences the residency time of the spray particles before deposition. In the case of plasma spray, the accelerated molten particles get deposited on to the substrate exposed to more environmental influence with higher standoff distance, however, in the case of detonation spray, increasing standoff distance resulting in enhanced interactions between particles and combustion flameleading to higher order plasticizing and better coating formation. Thus, it can be seen that while plasma spray is a dominant thermal process, the detonation spray is relatively a higher velocity impingement process.

In the case of plasma spraying, the injection of particles (to be sprayed) in the plasma flame results in

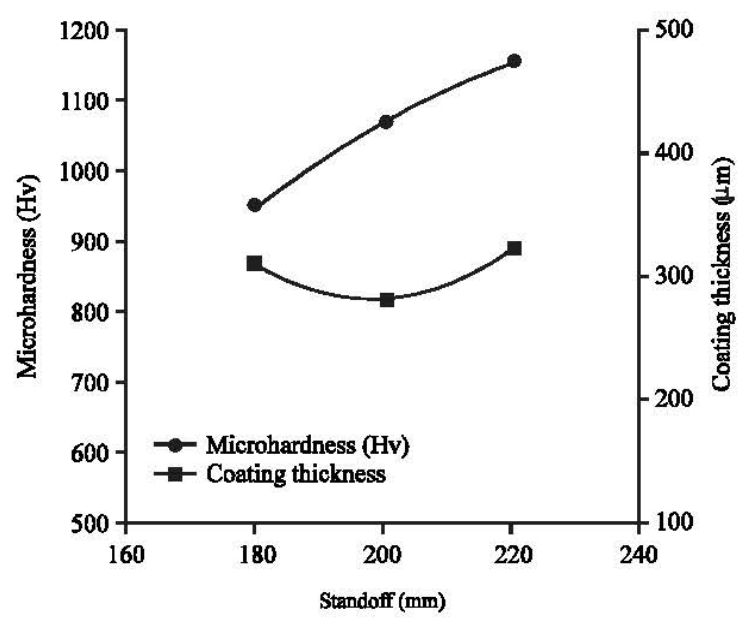

Fig. 1: Microhardness and coating thickness of as sprayed alum ina coating

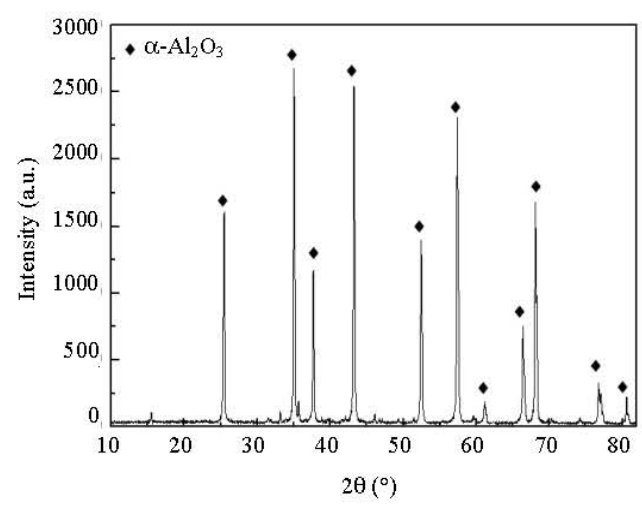

Fig. 2: XRD of alumina powder

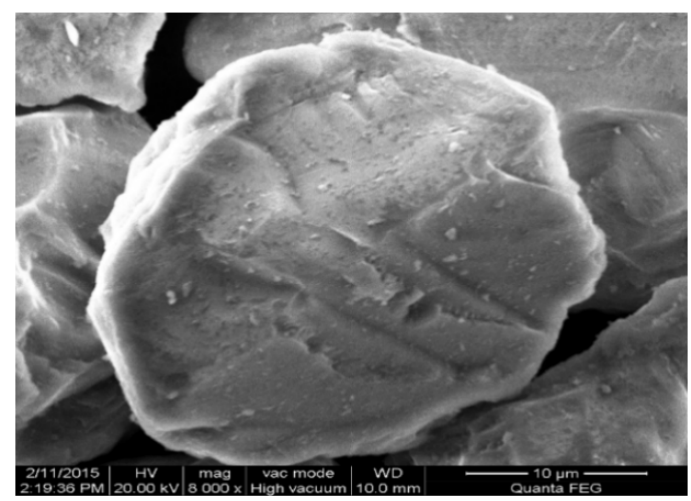

Fig. 3: SEM of alumina powder

melting and formation of high temperature ' $\gamma$ ' phase which on deposition resulting in presence of dominant high temperature ' $\gamma$ ' phase (kinetically stabilised) with the deposition (Gopalakrishnan, 1998). However, with detonation spraying relatively reduced order of $\alpha-\gamma$ 


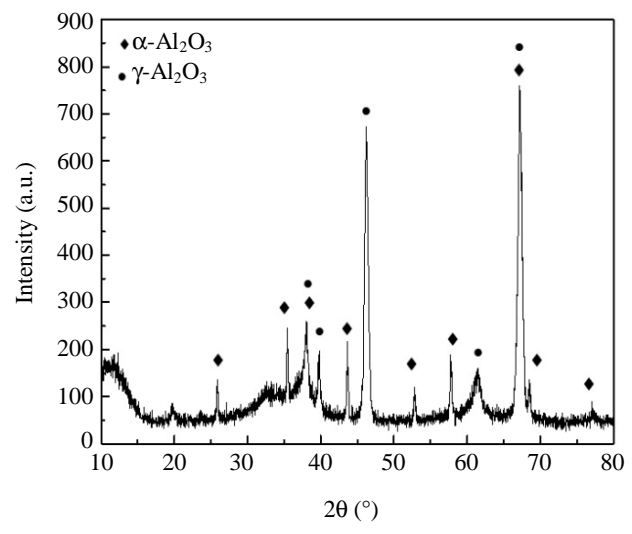

Fig. 4: XRD at standoff $-180 \mathrm{~mm}$

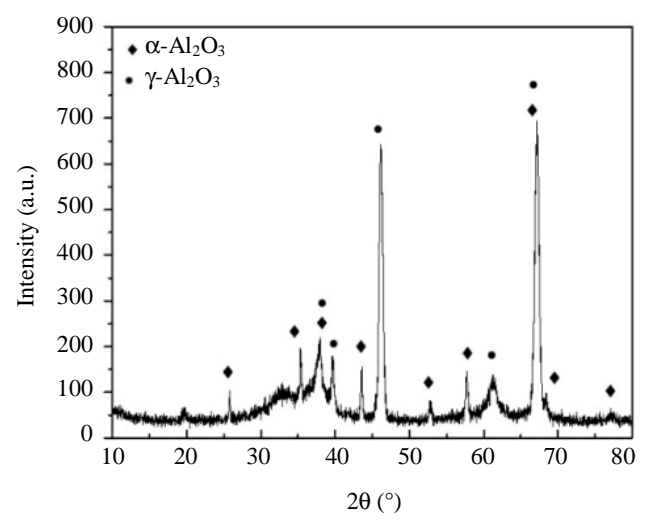

Fig. 5: XRD at standoff $-200 \mathrm{~mm}$

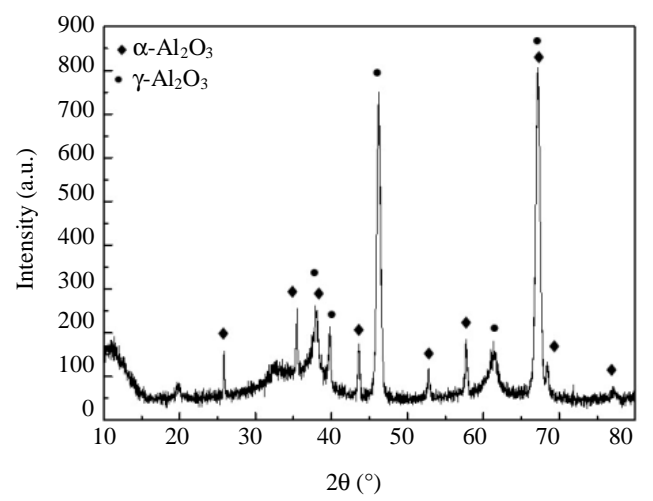

Fig. 6: XRD at standoff $-220 \mathrm{~mm}$

transformation has been observed. Comparing XRD patterns of raw alumina and sprayed alumina it is seen that the sprayed deposition contains fairly broadened peaks of ' $\alpha$ ' alumina in addition to peaks of ' $\gamma$ ' alumina. Also occurrence of relatively lower angle spikes (peaks) indicates formation of sub-grain which can lead to amorphous state. Higher velocity impingement of plasticized grains/particles causes higher order mechanical strain leading to sub-grain formation.

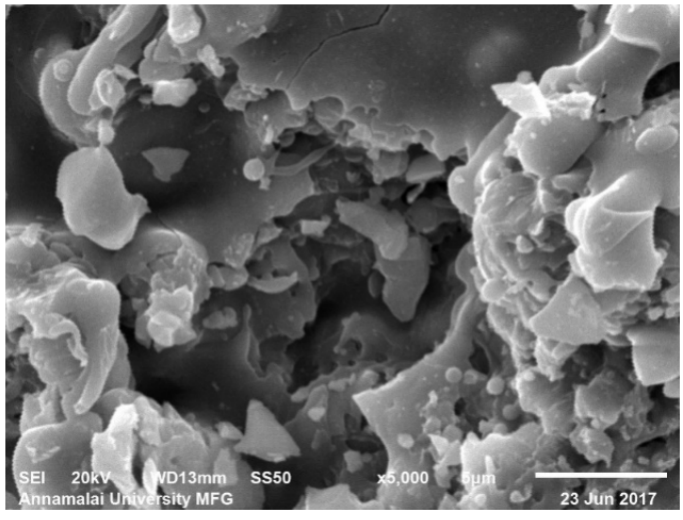

Fig. 7: SEM at standoff $-180 \mathrm{~mm}$

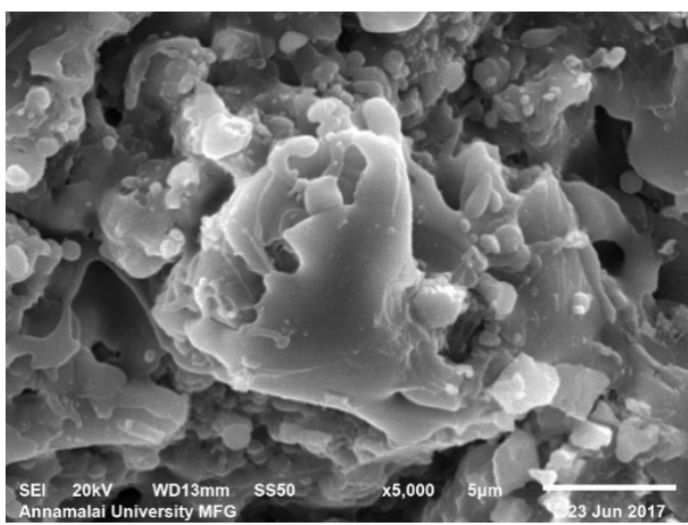

Fig. 8: SEM at standoff $-200 \mathrm{~mm}$

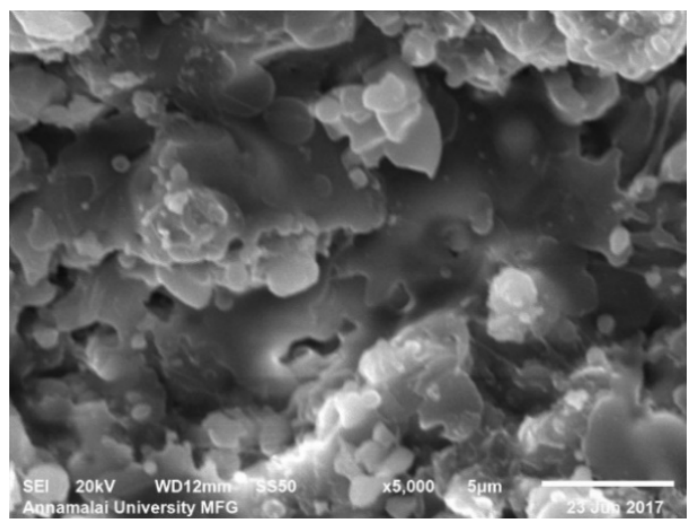

Fig. 9: SEM at standoff $-220 \mathrm{~mm}$

The micrograph of sprayed surface pertaining to different standoff distances (Fig. 7-9) supplement this. Relatively fragmented grains and discrete coalescent grains can be seen with $180 \mathrm{~mm}$ and $200 \mathrm{~mm}$ standoff. With $220 \mathrm{~mm}$ (Fig. 9), fairly uniform structure with less fragmentation can be seen. 
Wear characteristics: Figure 10 illustrates the tribological characteristics of detonation spray alumina deposition influenced by standoff distance. It is seen that sprayed surface encounters maximum wear when deposited with reduced standoff and a reduction in wear with increasing standoff. The progressive rise in hardness with standoff distance accounts for this. The fragmented particles of stressed subsurface could also contribute to the observed higher order wear. This also results in the observed trend of reduced coefficient friction with standoff distance. Figure 10 also illustrates frictional force variation with standoff. This shows that the sliding wear occurs with almost identical surface interaction attributable to dominant $\alpha$-phase with all the standoff distances.

Typical wear characteristics of the detonation sprayed alumina (on steel substrate) monitored during sliding wear trials is illustrated in Fig. 11a-c. Relatively

(a)

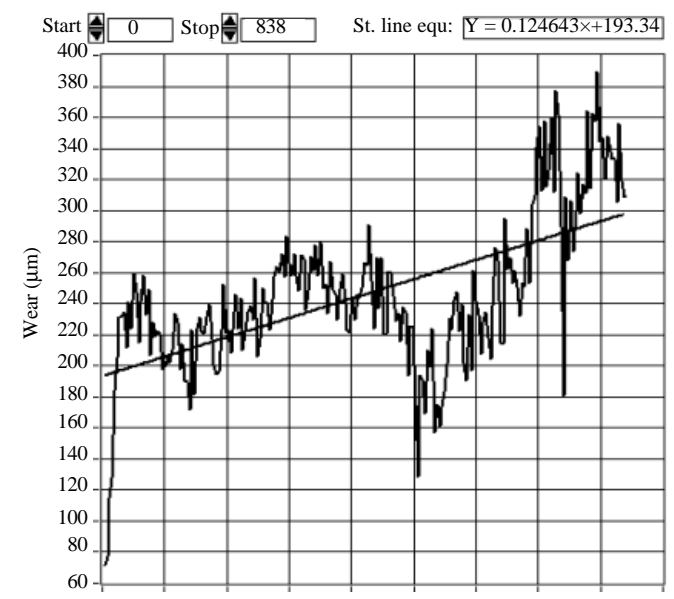

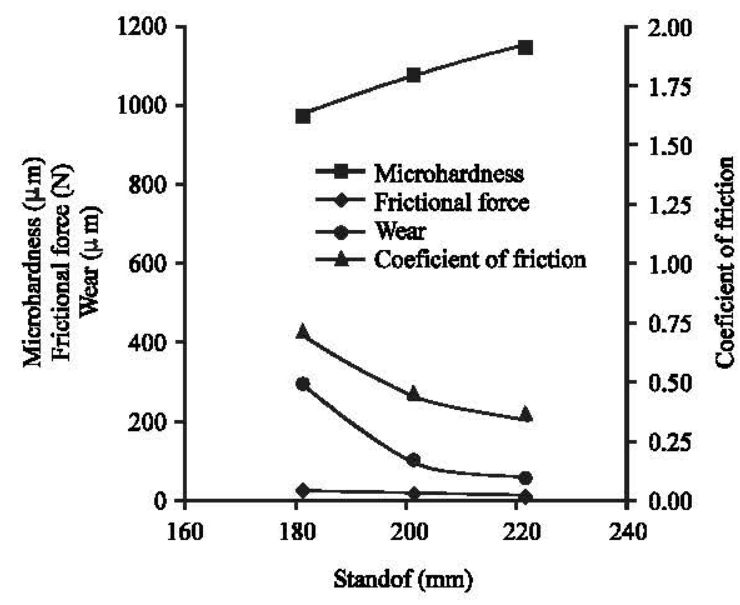

Fig. 10: Influence of standoff on microhardness, frictional force, wear and coefficient of friction

(b)

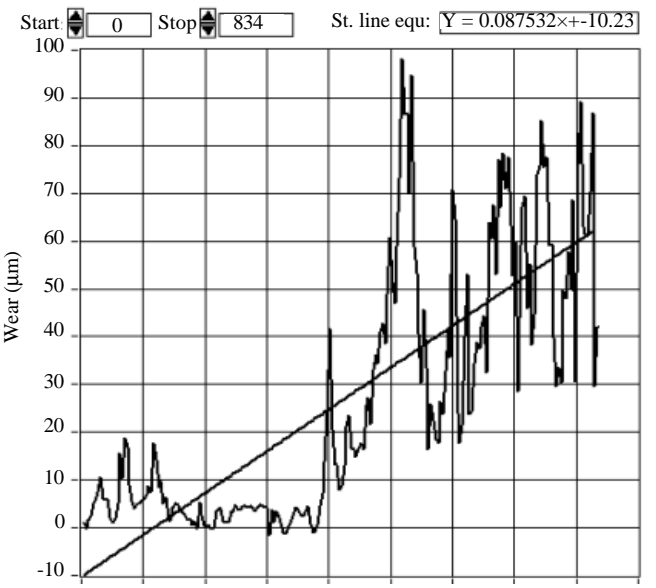

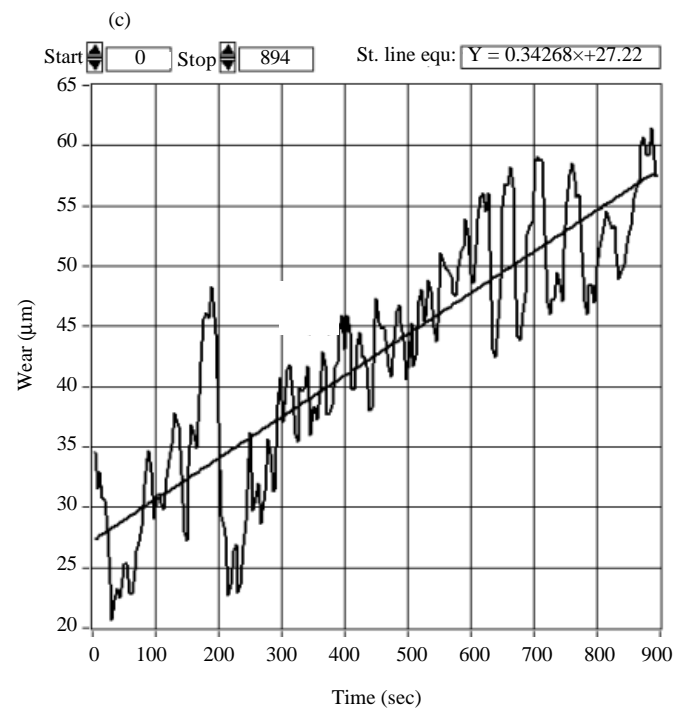

Fig. 11: Influence of standoff on sliding wear: a) $180 \mathrm{~mm}$; b) $200 \mathrm{~mm}$ and c) $220 \mathrm{~mm}$ 
(a)

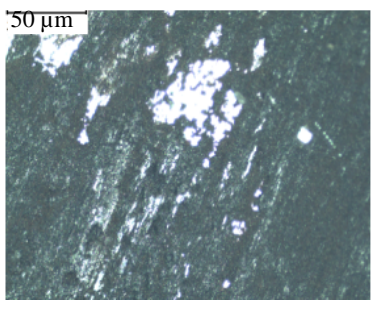

(b)

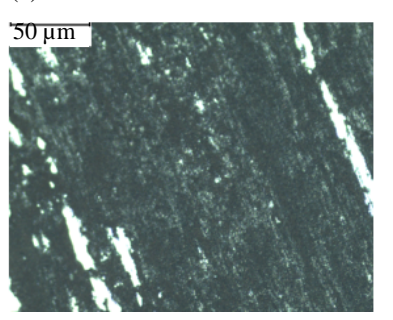

(c)

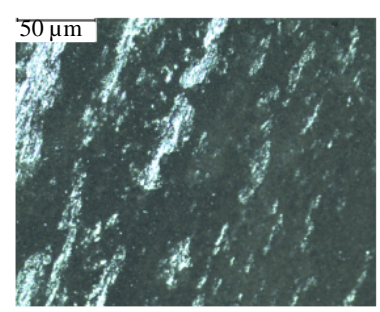

Fig. 12: Optical micrographs of the coated surface under sliding wear: a) $180 \mathrm{~mm}$; b) $200 \mathrm{~mm}$ and c) $220 \mathrm{~mm}$

higher order wear (least wear resistance) is seen with alumina deposition sprayed with $180 \mathrm{~mm}$ standoff. With standoff distance of $180 \mathrm{~mm}$, the deposition experiences a running-in wear of $280 \mu \mathrm{m}$ followed by a steady rise. Spraying with the standoff distance of $200 \mathrm{~mm}$ (Fig. 3b), the sprayed surface experiences a uniform wear till around 400 sec. Typical sliding wear track morphologies of coated specimens after pin-on-disc are given in Fig. 12. With increase in standoff, due to more residency, the coating and wear is more uniform as seen from Fig. $12 \mathrm{c}$.

\section{CONCLUSION}

The following are the findings of the characterisation of the detonation sprayed alumina coatings on unhardened EN19 steel:

The highest hardness value occurs at a spraying distance of $220 \mathrm{~mm}$ for the coatings deposited with oxygen-fuelratio of 1:2.5. Corresponding SEM micrograph indicates denser microstructure. XRD patterns indicate presence of $\gamma-\mathrm{Al}_{2} \mathrm{O}_{3}$ in addition to $\alpha$-phase on detonation sprayed coating.

Relatively higher order wear (least wear resistance) is seen with aluminaspray deposition with a standoff distance of $180 \mathrm{~mm}$. With standoff distance of $180 \mathrm{~mm}$, the deposition experiences a running-in wear of $280 \mu \mathrm{m}$ followed by a steady rise.

Typical sliding wear track morphologies of coated specimens after pin-on-disc test indicate more uniform wear at higher standoff due to more residency time.

\section{REFERENCES}

Balan, K.N. and B.R. Bapu, 2012. Process parameter optimization of Detonation Gun coating for various coating materials. Procedia Eng., 38: 3733-3740.

Chatha, S.S., H.S. Sidhu and B.S. Sidhu, 2012. Characterisation and corrosion-erosion behaviour of carbide based thermal spray coatings. J. Miner. Mater. Charact. Eng., 11: 569-586.
Du, H., C. Sun, J. Gong and S.W. Lee, 2007. Deposition and characterization of D-gun sprayed WC-co coating with self-lubricating property. Mater. Sci. Forum, 544: 215-218.

Dudina, D.V., I.S. Batraev, V.Y. Ulianitsky, N.V. Bulina and M.A. Korchagin et al., 2015. Detonation spraying of Ti-Al Intermetallics: Phase and microstructure development of the coatings. Mater. Manuf. Processes, 30: 724-729.

Gao, J.G., Z.H. Tang, C.L. Wang, M.Q. Guo and Y.J. Cui, 2015. Microstructure, mechanical and oxidation characteristics of detonation gun and HVOF sprayed MCrAlYX coatings. Trans. Nonferrous Met. Soc. China, 25: 817-823.

Geetha, M., S. Sathish, K. Chava and S.V. Joshi, 2014. Detonation gun sprayed $\mathrm{Al}_{2} \mathrm{O}_{3}-13 \mathrm{TiO}_{2}$ coatings for biomedical applications. Surf. Eng., 30: 229-236.

Gopalakrishnan, M.V., 1998. Processing, characterization and tribological studies in plasma spray formed ceramic composites. Ph.D Thesis, Indian Institute of Technology Madras, Chennai, India.

Kucuk, A., R.S. Lima and C.C. Berndt, 2001. Influence of plasma spray parameters on formation and morphology of $\mathrm{ZrO} 2-8$ wt\% Y2O3 deposits. J. Am. Ceram. Soc., 84: 693-700.

Kumar, R.S., L. Vijayaraghavan and M.M. Mayuram, 2011. Characterization and response evaluation of detonation-gun sprayed alumina-titania ceramic composite. Adv. Mater. Res., 264: 1468-1475.

Li, C.J. and A. Ohmori, 1996. The lamellar structure of a detonation gun sprayed Al2O3 coating. Surf. Coat. Technol., 82: 254-258.

Li, C.J. and A. Ohmori, 2002. Relationships between the microstructure and properties of thermally sprayed deposits. J. Therm. Spray Technol., 11: 365-374.

Rajakumar, S., L. Vijayaraghavan, M.M. Mayuram and R. Krishnamurthy, 2014. Sliding wear characterisation of D-gun sprayed alumina-based ceramic composite coatings. Intl. J. Abras. Technol., 6: 197-213. 
Rathore, P.S., S. Gulati, D. Li, G. Manivasagam and S.T. Aruna et al., 2013. Comparative Studies on Tribocorrosion Behaviour of Plasma-Sprayed and Detonation Gun Coatings of $\mathrm{Al}_{2} \mathrm{O}_{3}-13 \% \mathrm{TiO}_{2}$ on Biomedical Alloy Ti-13NB-13Zr and Gum Metal. In: Tribo-Corrosion: Research, Testing and Applications, Blau, P.J., J.P. Celis and D. Drees (Eds.). ASTM International, Atlanta, Georgia, ISBN:9780803175495, pp: 88-104.

Saladi, S., J.V. Menghani and S. Prakash, 2015. Characterization and evaluation of cyclic hot corrosion resistance of detonation-gun sprayed Ni-5Al coatings on inconel-718. J. Therm. Spray Technol., 24: 778-788.

Singh, L., V. Chawla and J.S. Grewal, 2012. A review on detonation gun sprayed coatings. J. Miner. Mater. Charact. Eng., 11: 243-265.
Srinivasan, D., 2016. Cold Spray-Advanced Characterization. In: High Pressure Cold Spray-Principles and Applications, Kay, C.M. and J. Karthikeyan (Eds.). ASM International, Geauga County, Ohio, pp: 121-130.

Wang, L., D. Yan, Y. Dong, J. Zhang and X. Chen, 2013. Nanostructured ceramic composite coating prepared by reactive plasma spraying micro-sized $\mathrm{Al}-\mathrm{Fe}_{2} \mathrm{O}_{3}$ composite powders. Ceram. Intl., 39: 2437-2442.

Wang, T.G., S.S. Zhao, W.G. Hua, J. Gong and C. Sun, 2009. Design of a separation device used in detonation gun spraying system and its effects on the performance of WC-Co coatings. Surf. Coat. Technol., 203: 1637-1644. 